\title{
Conceptualizing Person-environment Fit and the Meaning of Work for Tourist Guides in Malaysia During and Post COVID-19 Pandemic
}

\author{
Yen Phin Ng \\ Faculty of Business, Economics and Accountancy, Universiti Malaysia Sabah \\ Kota Kinabalu, Sabah, Malaysia \\ Oscar Dousin* (Corresponding author) \\ Faculty of Business, Economics and Accountancy, Universiti Malaysia Sabah \\ Kota Kinabalu, Sabah, Malaysia \\ E-mail: odousin@ums.edu.my/ oscardousin@gmail.com
}

Balvinder Kaur Kler* (Corresponding author)

Faculty of Business, Economics and Accountancy, Universiti Malaysia Sabah

Kota Kinabalu, Sabah, Malaysia

E-mail: balvinder@ums.edu.my

Received: Jan. 5, 2022 Accepted: Feb. 17, 2022 Online published: Mar. 1, 2022

doi:10.5296/ijhrs.v12i1.19435 URL: https://doi.org/10.5296/ijhrs.v12i1.19435

\begin{abstract}
This paper aims to conceptualizes the influence of person-environment fit (P-E fit) towards the meaning of work (MoW) for tourist guides (TGs) in Malaysia during and post-COVID-19 pandemic. TGs are key frontline workers whose employment is affected by the pandemic. A multilevel construct of P-E fit is adopted (person-organizational fit, person-job fit, and person-group fit) conceptualized as a correlation towards the tripartite work orientation of the MoW (job, career and calling). Four propositions emerge. Junior TGs view their work as a job and/or career; senior TGs perceive their work as a calling. Secondly, person-organizational fit and person-group fit has no influence with 'job', while person-job
\end{abstract}


fit could partially influence ' job' where demands-abilities has no influence on 'job' but need-supplies fit influences ' $j o b$ '. Next, person-organization fit and person-job fit correlate with guides' 'career' but not with person-group fit. Finally, all three fits relate to 'calling'. TGs with a 'job' relationship possess low meaning of work; 'career' has moderate meaning of work, and 'calling' experience high meaning of work. Practitioners benefit from knowledge of levels of correlations between constructs; useful for implementing resilience strategies for post crisis and beyond. A thorough understanding among TGs to remain engaged and motivated is useful for training courses.

Keywords: the meaning of work, person-environment fit, tourist guides, Malaysia

\section{Introduction}

Tourism was one of the key industries for economic growth in Malaysia. In 2018, the tourism sector contributed around RM84.1 billion to the Malaysian economy from 25.8 million tourist arrivals (Tourism Malaysia, 2019). However, the COVID-19 pandemic outbreak has negatively impacted the hospitality industry specifically tour companies, hotels, and airlines. The pandemic led to a negative growth of international tourist arrivals for the first half of 2020, a decrease of 68.2 per cent compared to 2019 (Tourism Malaysia, 2020). The tourism and hospitality industry in Malaysia suffered huge losses of around RM3.37 billion with the implementation of the movement control order (MCO) or lockdown (Dzulkifly, 2020). As such, the industry took drastic measures by shrinking operations through salary cuts, unpaid leave, retrenchment as well as termination which resulted in an increased rate of unemployment in this sector. Amidst this scenario, the plight of freelance tourist guides is truly unfortunate. The COVID-19 pandemic has severely affected this occupation due to the lack of tourists (de la Harpe \& Sevenhuysen, 2020; Benjamin et al., 2020). Most employed individuals were worried and concerned about their safety, financial losses, job insecurity and the fear of contagion. The situation has negative effects on their mental health (stress and depression) as well as their work performance (Hamouche, 2020).

Current literature provides limited discussion about resilience strategies of the tourism industry in the post COVID-19 situation, primarily in the Malaysian context (Khan \& Hashim, 2020). Specifically, limited studies focus on the context of TGs, even though they are seriously affected by the COVID-19 crisis (Grančay, 2020). Within the literature, there has been growing interest on the meaning of work (MoW) (see Wrzesniewski, 2003; Rosso et al., 2010; Martela \& Pessi, 2018) but most studies focus on general explanations of the MoW, instead of exploring a comprehensive view (Rosso et al., 2010). An in-depth explanation on the tripartite model of $\mathrm{MoW}$; job, career, and calling remains under-researched (Wrzesniewski et al., 2003). Conversely, extensive research has been conducted to investigate the related construct of person-environment fit (P-E fit) (see Morley, 2007; Su et al., 2015; Rahmadani \& Sebayang, 2017). However, the degree to which different types of P-E fit: person-organization fit (P-O fit), person-job fit (P-J fit), and person-group fit (P-G fit) could potentially act as antecedents to MoW have yet to be explored (Ünal, 2017). Since the pandemic has significantly changed tourism operations, this conceptualization provides an 
insight into how tourist guides in Malaysia perceive the meaning of work and its relations to P-E fit during and post COVID-19 pandemic. Although, TGs are mostly freelancers, tour companies need to better understand their guides since TGs services are essential to any tour operator which would contribute to their reputation and loyalty of tourists (Chan et al., 2015).

Employees' thriving or languishing is heavily influenced by their experiences in the work environment (Ryan \& Deci, 2011). Employees who are thriving experience their work as meaningful, have a positive perception of their job and find it interesting and engaging (Rothmann, 2014). More than a third of a person's life is spent in work-related activities (Wrzesniewski et al., 1997), the way people feel about their jobs has gotten a lot of attention. There are significant disparities in people's perspectives about their job (Wrzesniewski et al., 1997). As a result, work is an essential setting in which a person might find purpose and meaning (Cameron et al., 2003). Therefore, this study is timely as the issues of P-E fit and MoW among TGs could be applied to develop strategic human resource management solutions through a comprehensive model of P-E fit and MoW. This is critical to ensure that once the tourism industry is back in operation, TGs will be fully engaged and motivated with their work.

Hence, the aim of this paper is to explore the literature to conceptualize P-E fit as an antecedent to TGs' experiences and perceptions on the MoW during and post COVID-19 pandemic. This leads to the following four specific research objectives: (i) to examine TGs perception of work as a job, career, or calling, (ii) to conceptualize how P-O fit, P-J fit and P-G fit influence TGs 'job' orientation, (iii) to conceptualize how P-O fit, P-J fit and P-G fit influence TGs 'career' orientation and (iv) to conceptualize how P-O fit, P-J fit and P-G fit influence TGs 'calling' orientation. This novel paper is the first to adopt the multilevel construct of P-E fit: P-O fit, P-J fit, and P-G fit and its relation to the tripartite work orientation of the MoW; job, career and calling to conceptualize a study. We begin by reviewing related literature on MoW and P-E fit, before presenting the context of the study, TGs in Malaysia. Next, the discussion evaluates the literature on MoW for TGs, followed by a review of the relationship of P-E fit and the MoW. This discussion is the basis for a framework which examines TGs perception of work during and post COVID-19 to conceptualize the hypothesized the relationships for this study. The discussion section highlights the potential contribution of this study. Finally, we discuss practical implications, provide an overview of the limitations of this study and present opportunities for future work which aims at advancing the proposed conceptual framework.

\section{Literature Review}

\subsection{The Meaning of Work and Person-Environment Fit}

The meaning of work $(\mathrm{MoW})$ is a cognitive system of how an individual makes sense of the world of work which surrounds them (Wrzesniewski, 2003, p. 298). Work orientation is important to navigate individuals' fundamental aim for working, creating perceptions regarding the role of work in their life and how it connects their feelings and behaviour at 
work (Wrzesniewski et al., 1997). Moreover, work orientations could help to frame how an individual creates meaning from work and how they make their jobs meaningful (Wrzesniewski \& Dutton, 2001). The tripartite model consists of job, career, and calling.

Job orientation is defined as employee perceptions of work towards the provision of financial benefits to attain basic needs of the employee such as safety, psychology, and money with no interest for seeking other rewards (Wrzesniewski et al., 2003). The individual only works according to the required working time besides enabling them to enjoy free time from work. Therefore, the ambition and interest are express outside away from work through their hobbies or other interest (Wrzesniewski et al., 1997). Career orientation describes an individual who seeks opportunities for self-growth in relation to career advancement and achievement such as reputation, status, honor, professionalism, and salary increments (Wrzesniewski et al., 1997). These elements could increase self-esteem, higher power, and higher social standing which leads individuals to portray more of their self-identity while performing work (Wrzesnieski et al., 2003). Calling orientation refers to an individual's inner satisfactions or emotions toward work by improving their personal values which can contribute to other benefits (Wrzesniewski et al., 1997). The main purpose of calling is to attain meaning in life by contributing to the betterment of society (Steger, 2012). Thus, calling is considered as the highest level of $\mathrm{MoW}$ in that an individual with a calling work orientation believes in making their profession a positive influence, interesting and will embrace challenging work compared to those with job and career work orientations (Wrzesniewski et al., 1997).

Most studies focused on exploring the dimension of 'calling orientation', which motivates us to further explore the holistic concept of MoW to include 'job orientation' and 'career orientation'. As suggested by Scroggins (2008), there is a need to examine these three work orientations because of their influence on employees' attitudes, perceptions, and behaviors at work. Besides, there is an emerging trend to explore and investigate MoW antecedents and outcomes (see May et al., 2004; Pratt \& Ashforth, 2003; Cullen, 2013; Tan et al., 2019). Thus, to explore and examine MoW entirely as a concept is our first motivation for this study. As work occurs within the boundaries of employment and includes other people and the organization, we situate this study within the person-environment fit (P-E fit) theory (Chatman, 1989).

Chatman (1989) defined P-E fit as the suitability of an individual employee with their work environment. P-E fit can be achieved when an individual forms the environment and the environment forms the individual which is a continued process and reciprocal relationship (Rounds \& Tracey, 1990). The match between individual and their environment is important to improve positive employee and organizational outcomes, well-being, and effectiveness (Kristof-Brown et al., 2005). P-E fit has multilevel constructs including person-organizational fit (P-O fit), person- job fit (P-J fit), person group fit (P-G fit) (Werbel \& Gilliland, 1999).

Person-organizational fit (P-O fit) refers to compatibility between employee values and organization values, when one of the parties meets the needs of others, they share congruence 
characteristics, or both (Kristof-Brown, 1996, p. 4-6). These values are crucial aspects to decide P-O fit and may be obtained by recruiting employees' who share similar values with the organizational values (Chatman, 1989). Person-job fit (P-J fit) is defined as the suitability between the job demand with an employee's skill, knowledge, and abilities to ensure an employee knows and understands how to perform the job (Kristof-Brown et al., 2005, p. 284). This concept is measured by demands-abilities fit (D-A) and needs-supplies fit (N-S) (Cable $\&$ DeRus, 2002). D-A fit represents employees' skills, knowledge, and abilities to fit with the job demands, while N-S fit is how an employee perceives the adequacy between their job demand and job benefits such as salary and compensation, training, and promotion (KristofBrown et al., 2005). Next, person-group fit (P-G fit) is a match between an employee and members of the organization in term of values, goals, needs, preferences, working styles, characteristics, and skills that will determine the performance and cooperation of the group (Kristof- Brown et al., 2005, p. 286). These three P-E fit constructs are important to improve employee well-being, trust, positive work behaviors and attitudes, competence, comfort, satisfaction, and commitment (Kristof-Brown et al., 2005).

Studies on P-O fit and P-J fit have been extensively studied but P-G fit is neglected in the literature (Kristof-Brown, et al., 2005; Rahmadani \& Sebayang, 2017; Ünal, 2017; Stone et al., 2019). Thus, this is the second motivation for this paper, to explore and offer an insight into integrating all three constructs of P-E fit, as well as to provide an in-depth understanding on how these constructs are related to each other.

\subsection{Context of the Study: Tourist Guides in Malaysia}

Tourist guiding is a crucial occupation in the tourism industry. The European Federation of Tourist Guide Associations (2014) defined a tourist guide as an individual who guides both domestic and international tourists by elucidating the story of an attraction through the language preferred by tourists in an interesting way. In Malaysia, this profession commenced in the early 1960s and guides need to hold a valid TG license from the Ministry of Tourism and Culture Malaysia (MOTAC), Malaysia, under subsection 24 (1) (Tourism Industry Act, 1992). Besides a valid TG license, they also need to have comprehensive skills, knowledge, and abilities to become a TG.

Research on TGs in the tourism literature remains scarce even though the profession was identified as crucial for the industry (Widtfeldt Meged, 2010; Zillinger et al., 2012). Specifically, Grančay (2020) found that almost no studies have been conducted on how the COVID-19 pandemic has impacted the TGs profession even though the Organization for Economic Co-operation and Development (2020) highlighted the impact of the COVID-19 pandemic on this profession. Several studies on TGs in Malaysia are available but were conducted pre-COVID-19 pandemic. Hanani et al. (2013) revealed the positive relationship between TGs interpretation towards creating mindful tourists, learning, understanding and satisfaction in the context of Penang, Malaysia World Heritage Sites. Ali (2015) discovered the effectiveness of the Continuing Tourism Related Education (CTRE) in TGs career development besides improving their knowledge through training. Furthermore, Thoo (2015) 
and Polus et al. (2018) suggested that intrinsic rewards and continuous training is crucial to increase TGs job satisfaction, but not extrinsic rewards and job tenure. In sum, previous research in Malaysia focused mostly on TGs job satisfaction, while MoW studies for TGs remain limited. This is a critical issue as currently many TGs in Malaysia are severely impacted, forcing them to seek alternative work as an option to find income for survival (Lim, 2021). Due to its rich tourism attractions, marine life, and wildlife habitats, tourism is one of the three primary industries that contribute to the economy of Sabah, Malaysian Borneo (Official Website of the Sabah State Government, 2021). With an estimated 2,000 registered tourist guides (full-time and freelance), the state has one of the highest numbers of nature guides in the Malaysia (Holiday Sabah, 2021). For this reason, TGs in Sabah and Sarawak were chosen as the sample and their experiences as the context to explore the influence of P-E fit to MoW due to the gap in current HRM and tourism literature.

\subsection{The Meaning of Work for Tourist Guides}

To explore the MoW for TGs, we adopted the tripartite model of job, career, and calling. The focus of ' $j o b$ ' orientation is an employee will be motivated by monetary benefits and is influenced by the current economic situation (Antal et al., 2018). Employees will view work as valueable with a higher pay in a stressful work conditions, lower job rank and if they are married (Wrzesniewski et al., 2003; Wong et al., 2017). For employees with 'career' orientation, they are motivated to work for the monetary benefits as well as the opportunity for career growth in the organisation (Wrzesniewski, et al., 1997). Younger employees at a lower job rank tend to perceive their job with a 'career' orientation and they only strive for personal interest to experience work as meaningful (Wrzesniewski, et al., 1997). Chavadi et al. (2021) proved that personal growth become the main elements for millennials to affect their job satisfaction. Chopra and Bhilare (2020) also found that one of the critical factors of millennials' expectation for the future workplace is reward and recognition for their contribution. The 'calling' orientation is the highest level of MoW and this concept could be related to employees with a higher job-status who believe in making their profession a positive influence, interesting and embrace challenging work compared to employees in a low-status position (Wrzesniewski et al., 1997). This position is usually achieved after the employee reaches a higher rank position and develops the desire to strive to meet other higher needs which could contribute to a greater emotional well-being (Hershfield et al., 2016).

At present, numbers of studies examine the positive impact of 'calling' to employee outcomes and well-being (Wrzesniewski et al., 1997; Bunderson \& Thompson, 2009; Rosso et al., 2010). However, little research examines the influence of 'job' and 'career' orientation towards employee outcomes at an organizational level (Wrzesniewski, et al., 1997; Rijavec et al., 2016; Hu \& Hirsh, 2017). Several scholars state this could be due to these concepts being frequently associated with compensation, monetary benefits, and career choices (Wrzesniewski, et al., 1997; Wong et al., 2017). In addition, studies on how TGs perceived their work to establish their MoW is also scarce in the literature.

Based on the aforementioned literature, this study conceptualised 'job' orientation by 
presuming that junior TGs who are still at the early stage of their employment will be monetarily motivated during economic difficulties for their livelihood. In the study, junior TGs is an entry-level position with a TGs license, either a local nature tourist guiding or city tourist guiding (Ministry of Tourism, Art and Culture Malaysia, 2014). The study conceptualizes this position to individuals who have been working as TGs for at least 1-5 years. As for the 'career' orientation, this study defines this work orientation as junior TGs expectations and motivation to continuously develop their career with a dominant focus on work. The conceptualization is strengthened by Richardson (2010) who found Generation Y's concern on promotion opportunities, career paths and pay to work in tourism and hospitality industry.

Finally, an employee with a 'calling' orientation represents TGs who have extensive work experiences and achievements and are highly satisfied with 'job' and 'career' orientation. Thus, they will turn to achieve other levels of intrinsic motivation such as by perceiving that their profession as TGs will improve the knowledge of tourists and others besides being able to assist the tourism industry to promote tourist attractions. Therefore, the first hypothesis is:

H1: Junior TGs will perceive their work as a 'job or 'career' while senior TGs perceive their work as a 'calling'

\subsection{The Relationship between Person- Environment Fit and the Meaning of Work}

A study by Ghadi et al. (2015) revealed that MoW can be achieved when an (i) individual has a clear understanding of their expectations from their work; (ii) they feel congruence between their values and the organization's values and: (iii) has a clear understanding of how their role as an employee contributes to the goals of the organization. Therefore, the congruence between employee and their job (P-E fit) are considered as important antecedents of the MoW (Kristof-Brown, 1996). Furthermore, an important part of P-O fit is the compatibility between value, goals and belief between employee and employer, which could help to build MoW and psychological attachment that leads to improve employee engagement (Biswas \& Bhatnagar, 2013). During this pandemic and times of economic difficulty, employers need to be able to sustain their businesses and remain motivated to retain excellent employees', thus, $\mathrm{P}-\mathrm{O}$ fit is important. This study adopts three constructs of P-E fit, namely: P-O fit, P-J fit and $\mathrm{P}-\mathrm{G}$ fit elaborated next in relation to MoW.

\subsection{The Relationship Between P-O fit, P-J fit, and P-G Fit with 'Job' Orientation}

P-O fit emphasizes the crucial fit between an employee and their work processes (Werber \& De Marie, 2005). In a recent study by Dousin et al. (2020) P-O fit was identified as an important antecedent to improve employee job satisfaction and reduce their turnover intention. P-O fit emphasizes employees' perceptions on monetary benefits as their key motivation to work; they may portray less self-identity at work since they have no interest to feel compatible with their work content, thus, their work performance depends heavily on the 
willingness of the organization to offer a higher salary (Wrzesniewski et al., 2003). P-G fit refers to employees who do not spend time socializing with members of the organization because they are motivated with monetary benefits and to work according to the required working hours, which will enable them to enjoy free time from work (Wrzesniewski et al., 1997). Thus, there is no congruence values of P-O fit and P-G fit between TGs with job orientation and the employer.

Next, to measure P-J fit depends on employees' perceptions of the job itself (Cable \& DeRus, 2002). Demands-abilities (D-A) fit refers to an individual's ability to meet with the demands of their job requirements where they are only interested to gain financial benefits from their work (Cable \& DeRue, 2002). Employees with this work orientation have no interest whether their knowledge and skills meet the requirement of the job and are only motivated with the money they receive from their job (Wrzesniewski et al., 1997). In addition, they are more interested with their hobbies and other interests outside work (Wrzesniewski et al., 1997). Findings by De Crom and Rothmann (2018) revealed that the relationship between D-A fit and job orientation shows low work motivation. Therefore, this study anticipates that D-A fit may not be relevant to TGs who perceive their work as a 'job' orientation.

Additionally, needs-supply (N-S) fit refers to individual preferences which are provided and fulfilled by the organization in tandem to motivation with monetary benefits (Cable \& DeRue, 2002). Financial gain is seen as important to attain basic needs such as safety, psychology, and money with no interest to seek other rewards (Wrzesniewski et al., 2003). This work orientation is relevant among TGs in Sabah (Malaysian Borneo) during this pandemic. Since most lost their jobs, they turned to earning an income by selling food from home, insurance, as Grab drivers or grass cutting whilst their real livelihood is on pause (Sabah Tourism Board, 2020). As such, this study assumes that N-S fit is critically crucial for TGs who perceive money as their key motivation during COVID-19 to sustain a living. N-S fit could mediate the relations between psychological meaningfulness and employee engagement, as well as to improve employee job satisfaction by establishing employee feelings of meaningfulness and safety (Basit \& Arshad, 2016). Employees with high job satisfaction feel that the organization is concerned to meeting their needs which will encourage them to give back by improving their job engagement at work.

Based on the discussion above, it is suggested that only P-J fit (N-S fit) has a relationship with 'job' work orientation, while P-O fit, P-J fit (D-A fit) and P-G fit may not be relevant to this work orientation. Thus, P-E may have little influence towards TGs ' job' work orientation. Since TGs occupation has been heavily impacted during the COVID-19 pandemic, they might seek jobs in the future which could provide them with an adequate salary and job security to sustain their lives and the livelihood of their family. Wrzesniewski et al. (2003) argued that employees who feel in-congruence between their self and work will have no concern whether their work is meaningful or not. Therefore, we suggest the second hypotheses as:

H2 (a): P-O fit and P-G fit has no influence with 'job' work orientation while P-J fit could partially influence 'job' work orientation in a situation which $D$-A fit has no 
influence on 'job' orientation, but $N$-S fit will influence 'job' orientation.

H2 (b): TGs with 'job'work orientation will experience low level of MoW.

\subsection{The Relationship between $P$-O fit, $P$-J fit, and P-G fit with 'Career' Orientation}

TGs with 'career' work orientation will express more of their self-identity at work to gain achievement and accomplishment to strive for career development (Wrzesniewski et al., 1997). In this situation, P-O fit plays an important role to facilitate employees' career needs. To support these employees, at the organizational level, they are given opportunities to be promoted and offered any type of work or positions which could give them opportunities for hierarchical development (Abdalla et al., 2018). Employees who perceive that they are being given chances and opportunities will be willing to contribute to the organization by enhancing their job performance since it is crucial for their career development. The theory of work adjustment confirmed that an employee who feels that the organization could fulfill their needs will report higher job satisfaction and decreased intention to leave (Dawis \& Lofquist, 1984). Other studies reported similar results of P-O fit to provide positive employee outcomes such as job satisfaction, organizational commitment, and retention (Kristof-Brown et al., 2005; Dousin et al., 2020). The compatibility between TGs values and organizational values is important and beneficial for employees to experience work as meaningful.

Meanwhile, P-J fit in terms of D-A in the context of employees with a 'career' orientation who perceive their knowledge, skills, and abilities (KSA) to fit with the job demands influence their work reputation (Wrzesniewski et al.,1997). A professional TGs must be equipped with adequate competency and knowledge to provide detailed explanations on cultural and natural heritage, knowledge of policies, rules, laws, and practices of places to give greater understanding and enhancing the travel experience of tourists (Huang, 2010). Thus, TG's performance is crucial for their reputation and loyalty of the tourist (Chan et al., 2015). Therefore, TG who can meet the requirement of the job thus improve their work reputation and professionalism in their guiding tasks are factors which contribute towards employee MoW (Anuradha et al., 2014; Wong et al., 2017).

$\mathrm{N}-\mathrm{S}$ fit of an employee can be achieved when the organization could provide the opportunities for career advancement (Cable \& DeRue, 2002). Those employees who achieve adequate career advancement will have a high self-esteem and social standing with greater power at work (Wrzesniewski et al., 2003). In addition, a continuous effort of human resource development policies will assist organizations to improve their employer branding, which eventually improves employees' commitment and motivation (Lee \& Bruvold, 2003). Furthermore, N-S fit will also improve employee engagement and job satisfaction (Basit \& Arshad, 2016). Therefore, it is important to strengthen N-S fit and TGs 'career' orientation to improve their MoW.

However, employees with 'career' orientation have no interest to find values at work through interaction with other colleagues since they are only interested on self-growth for career advancement and achievement (Wrzesniewski et al., 1997) which could not be achieved 
through socialization with their co-workers. Hence, TGs who view their work as a 'career' feel in-congruence with P-G fit.

The review above revealed that P-O fit and P-J fit will influence employee 'career' orientation, while P-G fit seems irrelevant. In relation to TGs, P-E fit has a moderate impact on TGs who perceive their work as a 'career'. During the pandemic, this study assumes that TGs with a 'career' orientation have a moderate level of MoW. Due to the instability of the tourism business, these TGs are unable to expand their career in their organization if this pandemic prolongs. The situation could also influence them to change their career to meet their needs and wants. Therefore, we hypothesize:

$H 3$ (a): $P-O$ fit and P-J fit have significant relationships with TGs 'career' work orientation but not for $P-G$ fit.

H3 (b): TGs with a 'career'work orientation experience moderate level of MoW.

\subsection{The Relationship between P-O fit, $P-J$ fit, and P-G fit with Calling Orientation}

A crucial work value for those with 'calling' orientation is employees' cognitive work values which are related to their belief system on appropriate behaviors such as their contribution to communities to experience meaningful work (van Vianen et al., 2007). An organization with active Corporate Social Responsibilities (CSR) initiatives could attract employees with this work orientation because it will uplift their MoW (Supanti \& Butcher, 2019). A study by Afsar and Badir (2016) revealed that P-O fit crucial to influence organization behavior citizenship among employees. In relations to the TGs profession, the compatibility between employee's values and organization's values (P-O fit) will promote meaningful work provided the livelihood is enjoyable and they are pleased to work in a positive work environment.

An employee with 'calling' orientation is also motivated to search for novelty and challenges at work, improving their capabilities and encouraging continuous learning (Steger et al., 2012). They will actively share their knowledge and continuously performed a task which is perceived as meaningful, for instance, by crafting or customizing their job to meet the demand of the job requirements (D-A fit) (Lee, 2016). Job crafting is crucial and is an example of perceived meaningfulness in the modern work context because it is related to shifting employees' skills and needs to improve their job performance or to feel meaningful (Berg et al., 2010). As such, D-A fit is an antecedent to 'calling' orientation with high MoW, motivation and work engagement compared to 'job' and 'career' work orientation (De Crom \& Rothmann, 2018). Among TGs, D-A fit could be represented by intrinsic motivation which is important to improve their job satisfaction.

In terms of N-S fit, a fit occurs when the work environment satisfies an individual's needs, desires, or preferences (Kristof-Brown, 1996). An individual with 'calling' orientation belief of the work they do can bring positive impact for others (Wrzesniewski et al., 1997). Hence, if the job they do can meet the desires (N-S fit) and fulfill their unique purpose in life (calling), there will be harmony between themselves and their job which could facilitate them 
to experience MoW. Individuals with the opportunities to enact their 'calling' will experience work meaningfulness because they perceived their job as fulfilling and have a huge impact to their life (Dobrow, 2004). Therefore, we assume that N-S fit could facilitate TGs with a 'calling'work orientation to experience MoW.

At the socialization level, meaning is derived from being part of a particular group, while at the interpersonal level, meaning originates from the feeling of being connected with others (Rosso et al., 2010). Individuals with a 'calling' work orientation might be attracted to a group of people who share similar interests in contributing to a better world and establish a cohesive work relationship (Byrne, 1971). This will then improve their view of a meaningful work since they find it enjoyable and are happy to work in a positive work environment. A study by Mackenzie and Raymond (2020) found out that TGs well-being refers to their experience of positive interactions with fellow guides and tourists which encourages bonding, trust, and good times as a support system. However, Rosso et al. (2010) suggested the need to investigate how an employee pursues or enacts a 'calling'work orientation.

Wrzesniewski (2012) suggested that the highest level of MoW are individuals who experience and perceive their work as a 'calling'. This occupation bestows a sense of pride in their work, as the real ambassadors of a nation, which might be the reason why TGs aspire to continue this profession during (some have taken to providing free recorded walking tours published online) or after this pandemic and even at a senior age because they perceive that a guide never retires. The COVID-19 pandemic has obviously impacted the profession, yet TGs who possess a 'calling' work orientation will remain loyal to their job. Although they might find other temporary jobs to earn income for survival, they have no intention to change careers because they have a sense of pride in their knowledge and experience in the job. A study by Rijavec et al. (2013) found that even during economic difficulties, employees' still view their work as a 'calling' and reported higher job satisfaction. Thus, these TGs have confidence that the tourism industry will soar again as soon as borders reopen which encourages them to experience a higher MoW. This raises the fourth hypotheses of the study:

$H 4$ (a): $P-O$ fit, $P-J$ fit, and $P-G$ fit have significant relationship with 'calling' work orientation.

H4 (b): TGs who perceive their work as a 'calling' will experience higher MoW compare to those with a 'job' and 'career' work orientation.

Figure 1 below indicates the proposed conceptual framework of the study. 


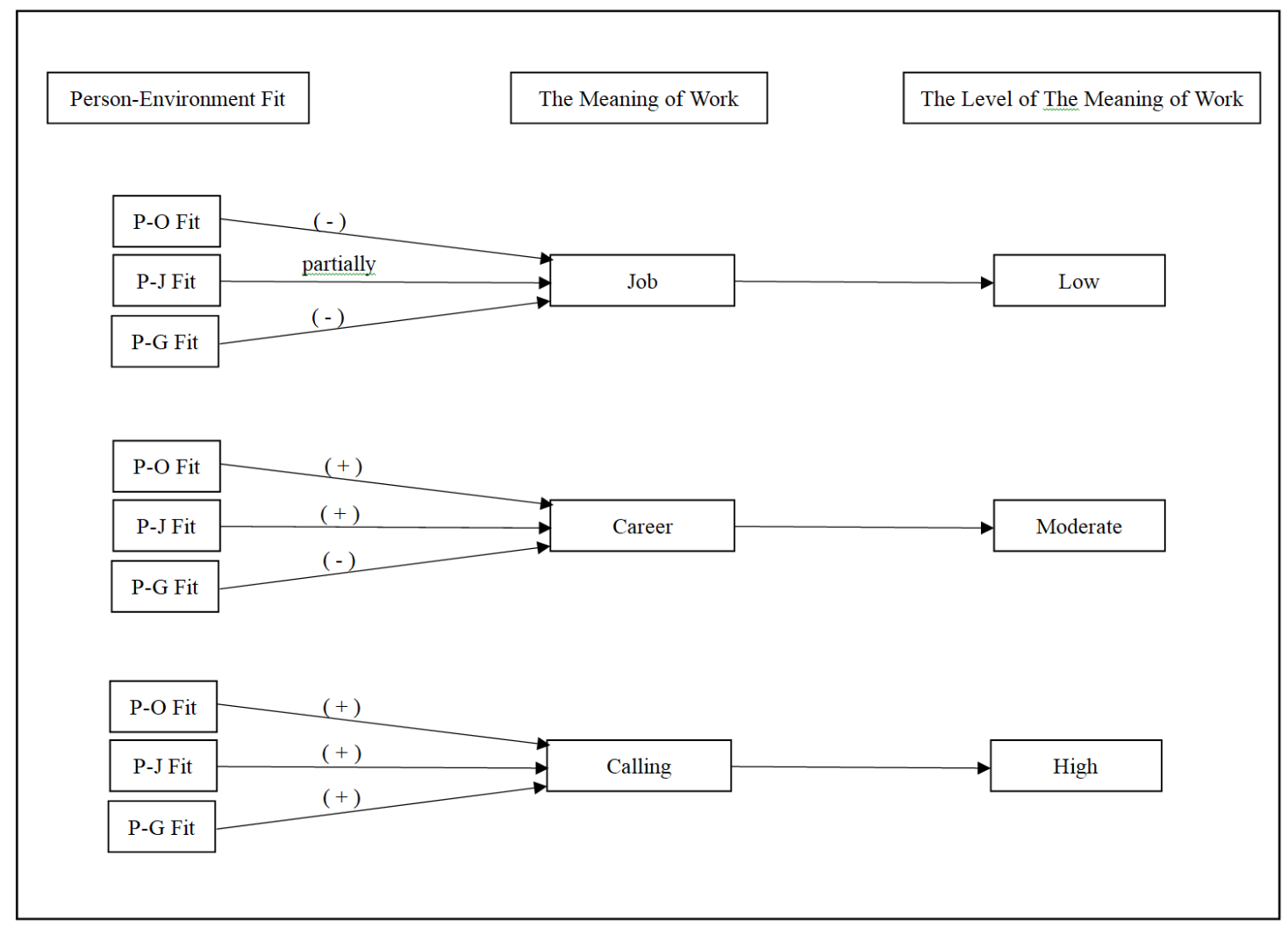

Figure 1. Conceptual Framework

\section{Discussion}

The global pandemic has adversely impacted the tourism industry and occupations within it, TGs are one example. Therefore, the MoW model sheds light into the critical P-E fit to understand how work holds important meaning to TGs livelihoods, especially during this global crisis. Presently, many TGs have found other temporary jobs for survival during these difficult times such as selling homemade food online, as a runner for food delivery companies and even volunteers to distribute aid. Sadly, these jobs will not provide intrinsic satisfaction. The aim of the study was to propose a conceptualization of the relationship between the multilevel constructs of P-E fit and MoW among TGs. Theoretically, the study expands the conceptualization of P-E fit and MoW in the HRM and tourism literature. At present, there is little research which examines the comprehensive dimensions of P-E fit. For instance, previous studies examined P-J fit (Scroggins; 2008; Ünal, 2017; De Crom \& Rothmann, 2018; Sylva et al., 2019) and P-O fit (Kristof-Brown; 1996; James, 2003; van Vianen et al., 2007) separately. Generally, studies investigate positive outcomes of P-O fit and P-J fit (Rahmadani \& Sebayang, 2017; Stone et al., 2019), studies on P-G fit are limited. Besides, we followed suggestions by several researchers that a distinct level of fit in P-E fit should be studied with different dimensions and outcomes (Werbel \& Gilliland, 1999; Su et al., 2015). This study offers a conceptualization for the relationship between P-E fit and MoW, which not only contributes to an understanding of these two concepts but also the advances person-fit theory since there is a lack of studies which examine which types of P-E fit can become antecedents to MoW (Ünal, 2017). 


\subsection{Practical Implications}

A number of practical implications are raised by this study. An examination of the conceptualization between the multilevel constructs of P-E fit and MoW could contribute to developing employment policies which benefit the well-being of TGs. Findings of the study could provide a comprehensive understanding for the government, tour company management and employees of the tourism industry on how TGs shape their opinions, feelings, and behavior towards their profession to experience work as meaningful. Job, career, or calling: each dimension contributes practical suggestions for different players. For example, during the pandemic laden with economic difficulties, monetary benefits were crucial for survival especially for junior TGs. Findings could provide evidence for the government sector to enhance financial assistance for all TGs. In addition, knowledge of 'career' orientations would enable top management and organization HR manager to improve future recruitment, training, upskilling, and reskilling for TGs. Besides that, many tour companies chose to downsize their operations during these difficult times. The knock-on effect on TGs included uncertainty about job security and financial losses which could negatively affect their self-esteem. Some have questioned their job role. Hence, P-E fit is an important type of perceptual fit on how an individual employee feels and perceives work which is useful for strategic organizational retention management initiatives (Scroggins, 2008). The integration of positive MoW will benefit the organization through higher employee engagement and loyalty. As such, as soon as the pandemic is under control, the government will re-open the tourism industry and allow TGs to return to work in the field of their choice where they feel their work is meaningful and significant.

\subsection{Limitations and Future Research}

At present, few studies have explored the comprehensive understanding of MoW, besides survey instruments are still limited and scarce in the literature. Wrzesniewski et al. (1997) developed an instrument in their first empirical study on MoW, to investigate the three-work orientations namely job, career, and calling. To date, this instrument remains the only MoW measurement. Moreover, previous studies only focused on the concept of 'calling' which is a well-developed measure since this orientation is most promising and more rewarding than job and career (Rijavec et al., 2016). Future work could enrich and extend the instrument to provide beneficial contributions to the literature on the MoW in the context of TGs. Precisely, this paper has successfully conceptualized the relationship between the multilevel constructs of P-E fit and MoW among TGs. Thus, future work is needed through empirical studies to confirm and support the proposed relationships in this conceptualization by applying an explanatory mixed-methods approach to leverage a better understanding of the link between P-E fit and MoW. Mixed method studies are valuable as combining quantitative and qualitative approaches enables phenomena to be understood more fully by capturing the rich, personal experience of participants (Dousin, 2017; Dousin et al., 2021; Weeks \& Schaffert, 2019). In phase one, the quantitative study will obtain an understanding of the relationships between the multilevel constructs of P-E fit and MoW among TGs in Malaysia. A qualitative study in phase two will further explore and clarify on the results of phase one through 
in-depth exploration of the TGs opinions about the topic based on their own experience. Findings would provide a thorough explanation of the relationships between P-E fit and MoW which could be pertinent to the way we understand work orientation for TGs.

\section{Conclusion}

This study proposed a novel conceptual framework by situating P-E fit as an antecedent to TGs' experiences and perceptions on the MoW during and post COVID-19 pandemic. Four specific research objectives were conceptualized after a critical review of the extant literature. The first objective was to examine how TGs perceive their work orientation. The literature clarifies and supports the use of the tripartite model of job, career, and calling to understand the work orientation of TGs. Each orientation was deliberated in terms of motivations, work conditions, ranks, demographics, and aspirations indicating clear differences between junior and senior guides. This understanding was used to guide the development of subsequent hypotheses. As yet, empirical data on MoW for TGs remains unexplored. Next, the second objective examined how P-O fit, P-J fit and P-G fit influence TGs 'job' orientation. The literature suggests that only P-J fit could partially influence 'job' and only when N-S fit influences this work orientation. In this situation, TGs would experience a low level of MoW. Thirdly, we examined how P-O fit, P-J fit and P-G fit influence TGs 'career' orientation. Here, the literature indicates that only P-O fit and P-J fit have significant relationships with TGs 'career' work orientation. A such, TGs with a 'career' work orientation would experience a moderate level of MoW. The fourth and final objective was to examine how P-O fit, P-J fit and P-G fit influence TGs 'calling' orientation. The literature supports that all fits, P-O, P-J and P-G have significant relationships with 'calling' work orientation. Moreover, TGs who perceive work as a 'calling' will experience higher MoW compared to those with a 'job' and 'career' work orientation. This conceptual study has provided a critical understanding about MoW as the perceived purpose and motivation at work which relates to how an individual thinks and feels about work. Amidst the pandemic, this conceptualization provides a useful insight of how P-E fit could potentially influence TGs perception of meaningful work.

\section{References}

Abdalla, A., Elsetouhi, A., Negm, A., \& Abdou, H. (2018). Perceived person organization fit and turnover intention in medical centers: The mediating roles of person-group fit and person-job fit perceptions. Personnel Review, 47(4), 863-881.

Ali, S. (2015). The effectiveness of Continuing Tourism Related Education (CTRE) for tourist guides in Malaysia [University Teknology Malaysia]. http://eprints.utm.my/id/eprint/53600/1/SurayahanimAliMFAB2015.pdf

Antal, A. B., Debucquet, G., \& Frémeaux, S. (2018). Meaningful work and artistic interventions in organizations: Conceptual development and empirical exploration. Journal of Business Research, 85, 375-385. 
Anuradha, M. V, Srinivas, E. S., Singhal, M., \& Ramnarayan, S. (2014). To work, or not to work? Vikalpa, 39(2), 7-19.

Basit, A. A., \& Arshad, R. (2016). The role of needs-supplies fit and job satisfaction in predicting employee engagement. Jurnal Pengurusan, 47, 3-12.

Benjamin, S., Dillette, A., \& Alderman, D. H. (2020). We can't return to normal: Committing to tourism equity in the post-pandemic age. Tourism Geographies, 22(3), 476-483.

Berg, J. M., Wrzesniewski, A., \& Dutton, J. E. (2010). Perceiving and responding to challenges in job crafting at different ranks: When proactivity requires adaptivity. Journal of Organizational Behavior, 31, 158-186.

Biswas, S., \& Bhatnagar, J. (2013). Mediator analysis of employee engagement: Role of perceived organizational support, P-O fit, organizaional commitment and job satisfaction. Research, 38(1), 27-40.

Bunderson, J. S., \& Thompson, J. A. (2009). The call of the wild: Zookeepers, callings, and the double-edged sword of deeply meaningful work. Administrative Science Quarterly, 54, $32-57$.

Byrne, D. (1971). The attraction paradigm. New York: Academic Press.

Cable, D. M., \& DeRus, D. S. (2002). The convergent and discriminant validity of subjective fit perceptions. Journal of Applied Psychology, 87(5), 875-884.

Cameron, S., Dutton, J., \& Quinn, R. (2003). Positive organizational scholarship: Foundations of a new discipline. San Francisco, CA: Berrett-Koehler Publishers.

Chan, A., Hsu, C. H. C., \& Baum, T. (2015). The impact of tour service performance on tourist satisfaction and behavioral intentions: A study of Chinese tourists in Hong Kong. Journal of Travel and Tourism Marketing, 32(1-2), 18-33.

Chatman, J. A. (1989). Improving interactional organizational research: A model of person-organization fit. Academy of Management Review, 14, 333-349.

Chavadi, C. A., Sirothiya, M., \& Vishwanatha, M. R. (2021). Mediating role of job satisfaction on turnover intentions and job mismatch among Millennial employees in Bengaluru. Business Perspectives and Research, 1-22.

Chopra, A., \& Bhilare, P. (2020). Future of work: An empirical study to understand expectations of the Millennials from organizations. Business Perspectives and Research, $8(2)$, $272-288$.

Cullen, J. G. (2013). Vocational ideation and management career development. Journal of Management Development, 32(9), 932-944.

Dawis, R. V., \& Lofquist, L. H. (1984). A psychological theory of work adjustment. University of Minnesota Press, Minneapolis.

De Crom, N., \& Rothmann, S. (2018). Demands-abilities fit, work beliefs, meaningful work 
and engagement in nature-based jobs. SA Journal of Industrial Psychology, 40(0), 1-12.

De la Harpe, M. Sevenhuysen, K. (2020). New technologies in the field of tourist guiding: threat or tool? Journal of Tourismology, 5(1), 1-21.

Dobrow, S. (2004). Extreme subjective career success: A new integrated view of having a calling. Academy of Management Proceeding, 1, 1-6.

Dousin, O., Toh, P. S., Bahron, A., \& Rahim, I. H. A. (2020). Does person-organization fit (P-O fit) mediate the relationship between employee job satisfaction and turnover intention: The case of insurance agents in Malaysia. International Journal of Human Resource Studies, 10(2), 117-130.

Dzulkifly, D. (2020). Tourism industry hit hardest by Covid-19, faces RM3.37b loss. Malay Mail.

https://www.malaymail.com/news/malaysia/2020/03/13/muhyiddin-tourism-industry-hithardBy-covid-19-to-loserm3.37b-while-gdp-s/1846323

European Federation of Tourist Guide Associations. (2014). About FEG. http://www.feg-touristguides.com/\%0Aabout-feg.html.

Ghadi, M. Y., Fernando, M., \& Caputi, P. (2015). Describing work as meaningful: towards a conceptual clarification. Journal of Organizational Effectiveness: People and Performance, 2(3), 1-38.

Grančay, M. (2020). COVID-19 and governmental measures to support tourist guides: A research note. Munich Personal Archive. https://mpra.ub.uni-muenchen.de/102382/1/MPRA_paper_102382.pdf

Hamouche, S. (2020). COVID-19 and employees' mental health: Stressors, moderators and agenda for organizational actions. Emerald Open Research, 2(15), 1-15.

Hanani, N. E., Mohamed, R., Md Noor, S., \& Khor, Y. L. (2013). The effectiveness of tour guide's interpretation in creating mindful tourists: A study on the Penang world heritage sites. Proceedings of International Conference on Tourism Development.

Hershfield, H. E., Mogilner, C., \& Barnea, U. (2016). People who choose time over money are happier. Social Psychological and Personality Science, 7(7), 697-706.

Hu, J., \& Hirsh, J. B. (2017). Accepting lower salaries for meaningful work. Frontiers in Psychology, 8(1649), 1-10.

Huang, S. (2010). A revised importance-performance analysis of tour guide performance in China. Tourism Analysis, 15(2), 227-241.

James, I. L. (2003). Employees as stakeholders: An examination of person-organization fit and corporate social performance.

Khan, M. A., \& Hashim, H. (2020). The effect of COVID-19 on tourism and hospitality industry in Malaysia, resurgence in the post-pandemic era: A conceptual criterion. 
International Journal of Tourism \& Hospitality Reviews, 7(2), 54-62.

Kristof-Brown, A. L. Zimmerman, R. D., \& Johnson, E. C. (2005). Consequences of individuals' fit at work: A meta-analysis of person-job, person-organization, person-group, and person-supervisor fit. Personnel Psychology, 58(2), 281-342.

Kristof-Brown, A. L. (1996). Person-organization fit: An integrative review of its conceptualizations, measurement, and implications. Personnel Psychology, 49, 1-49.

Lee, C. H., \& Bruvold, N. T. (2003). Creating value for employees: Investment in employee development. The International Journal of Human Resource Management, 14(6), 981-1000.

Lee, K. J. (2016). Sense of calling and career satisfaction of hotel frontline employees: Mediation through knowledge sharing with organizational members. International Journal of Contemporary Hospitality Management, 28(2), 346-365.

Lim, J. (2021, February). Rough guide for tour guides. The Star. https://www.thestar.com.my/metro/metro-news/2021/02/19/rough-guide-for-tour-guides

Mackenzie, S. H., \& Raymond, E. (2020). A conceptual model of adventure tour guide well-being. Annals of Tourism Research, 84, 1-14.

Martela, F., \& Pessi, A. B. (2018). Significant work is about self-realization and broader purpose: Defining the key dimensions of meaningful work. Frontiers in Psychology, 9(363), $1-15$.

May, D., Gilson, R., \& Harter, L. (2004). The psychological conditions of meaningfulness, safety and availability and the engagement of the human spirit at work. Journal of Occupational and Organizational Psychology, 77, 11-37.

Morley, M. J. (2007). Person-organization fit. Journal of Managerial Psychology, 22(2), $109-117$.

Polus, R. @ C., Jussem, P. M., \& Chung, E. (2018). Job satisfaction among regional specific tourist guides: Evidence from Malaysian Borneo. International Journal of Academic Research in Business and Social Sciences, 8(16), 103-121.

Pratt, M. G., \& Ashforth, B. E. (2003). Fostering meaningfulness in working and at work BT Positive organizational scholarship: Foundations of a new discipline. In Cameron (Ed.), Positive Organizational Scholarship: Foundations of a New Discipline. San Francisco: Brrett-Koehler.

Rahmadani, I. G., \& Sebayang, I. R. (2017). The influence of person-organization fit and person-job fit on work engagement among policemen in Sumatera Utara. International Journal of Management Science and Business Administration, Inovatus Services Ltd, 4(1), 45-51.

Rijavec, M., Pečjak, S., Jurčec, L., \& Gradišek, P. (2016). Money or career or calling? Intrinsic vs. extrinsic work orientations and job satisfaction of Croatian and Slovenian Teachers. Croatian Journal of Education, 18(1), 201-223. 


\section{Macrothink}

International Journal of Human Resource Studies ISSN 2162-3058 2022, Vol. 12, No. 1

Rosso, B. S., Dekas, K. H., \& Wrzesniewski, A. (2010). On the meaning of work: A theoretical integration and review. Research in Organizational Behavior, 30, 91-127.

Rothmann, S. I. (2014). Flourishing in work and careers. In I. M. Coetzee (Ed.), Psycho-social career meta-capacities: Dynamics of contemporary career development (pp. 203-220). Springer International Publishing AG.

Rounds, J. B., \& Tracey, T. J. (1990). From trait-andfactor to person-environment fit counseling: Theory and process. In W. B. Walsh \& S. H. Osipow (Eds.), Career Counseling: Contemporary Topics in Vocational Psychology. Hillsdale, NJ, US: Lawrence Erlbaum Associates, Inc.

Ryan, R. M., \& Deci, E. L. (2011). A self-determination theory perspective on social, institutional, cultural, and economic supports for autonomy and their importance for well-being. In \& K. M. S. In V. I. Chirkov, R. M. Ryan (Ed.), Human autonomy in cross-cultural context: Perspectives on the psychology of agency, freedom, and well-being (pp. 45-64).

Sabah Tourism Board. (2020). Since the pandemic outbreak, his company has made zero income. No income equals no salary and no employment. However, as a breadwinner, Hans still has monthly expenses and a family to care of. He is now offering grass-cutting service around the town. https://www.instagram.com/p/CHhUkhypBbE/?igshid=u3ntez13d30u

Scroggins, W. a. (2008). Antecedents and outcomes of experienced meaningful work: A person-job fit perspective. Journal of Business Inquiry, 7(1), 68-78.

Steger, M. F. (2012). Making meaning in life. Psychological Inquiry, 23(4), 381-385.

Steger, M. F., Dik, B. J., \& Duffy, R. D. (2012). Measuring meaningful work: The Work and Meaning Inventory (WAMI). Journal of Career Assessment, 20(3), 322-337.

Stone, R. P., Leuty, M. E., Rayburn, R., \& Wu, B. H. (2019). Person-environment fit at work: Relationships with workplace behaviours. Australian Journal of Career Development, 28(3), 234-244.

Su, R., Murdock, C., \& Rounds, J. (2015). Person-Environment Fit. In P. J. Hartung, M. L. Savickas, \& W. B. Walsh (Eds.), The Encyclopedia of Adulthood and Aging (APA Handbo). American Psychological Association.

Supanti, D., \& Butcher, K. (2019). Is corporate social responsibility (CSR) participation the pathway to foster meaningful work and helping behavior for millennials? International Journal of Hospitality Management, 77, 8-18.

Sylva, H., Mol, S. T., \& Den Hartog, D. N. Dorenbosch, L. (2019). Person-job fit and proactive career behavior: a dynamic approach. European Journal of Work and Organizational Psychology, 28(5), 631-645.

Tan, K.-L., Lew, T.-Y., \& Sim, A. K. S. (2019). An innovative solution to leverage meaningful work to attract, retain and manage Generation Y employees in Singapore's hotel 
industry. Worldwide Hospitality and Tourism Themes, 11(2), 2014-2216.

The Organization for Economic Co-operation and Development. (2020). Tourism Policy Responses to the corona-virus (COVID-19). https://www.oecd.org/coronavirus/policy-responses/tourism-policy-responses-to-the-coronavi rus-covid-19-6466aa20/

Thoo, I. (2015). Job satisfaction among licensed tourist guide in Malaysia. Universiti Tunku Abdul Rahman, Malaysia.

Tourism Industry Act. (1992). Tourism Industry Act 1992. Laws of Malaysia Act 482. https://gotraz.com.my/wp-content/uploads/2021/04/TOURISM-INDUSTRY-ACT-1992.pdf

Tourism Malaysia. (2019). Tourist arrivals \& receipts to Malaysia by year. https://corporate.tourism.gov.my/statistics

Tourism Malaysia. (2020). Negative growth of $68.2 \%$ for tourist arrivals in the first half of $2020 . \quad$ Media Releases. https://www.tourism.gov.my/media/view/negative-growth-of-68-2-for-tourist-arrivals-in-the-f irst-half-of-2020

Ünal, Z. M. (2017). The mediating role of meaningful work on the relationship between needs for meaning-based person-job fit and work-family conflict. International Scientific Conference on Sustainable Development, 332-338.

van Vianen, A. E. M., Shen, C.-T., \& Chuang, A. (2007). Person-organization and person-supervisor fits: Employee commitments in a Chinese context. Journal of Organization Behavior, 32(6), 906-926.

Weeks, K. P., \& Schaffert, C. (2019). Generational differences in definitions of meaningful Work: A mixed methods study. Journal of Business Ethics, 156(4), 10.

Werbel, J. D., \& Gilliland, S. W. (1999). Person-environment fit in the selection process. In G. R. Ferris (Ed.), Research in human resource management (pp. 209-243). Elsevier Science/JAI Press.

Werber, J., \& De Marie, S. M. (2005). Aligning strategic human resource management and person-environment fit. Human Resource Management Review, 15(4), 247-262.

Widtfeldt Meged, J. (2010). The guided tour: A co-produced tourism performance. Department of Environmental, Social and Spatial Changes, Roskilde University.

Wong, I. K. A., Wan, Y. K. P., \& Gao, J. H. (2017). How to attract and retain Generation Y employees? An exploration of career choice and the meaning of work. Tourism Management Perspectives, 23, 140-150.

Wrzesniewski, A. (2003). Finding positive meaning in work. In J. E. Cameron, J. E. Dutton, \& R. E. Quinn (Eds.), Positive Organizational Scholarship: Foundations of a New Discipline (1st ed., pp. 298-308). San Francisco: Berrett-Koehler. 
Wrzesniewski, A. (2012). Callings (In K. Came). New York: Oxford University Press.

Wrzesniewski, A., \& Dutton, J. E. (2001). Crafting a job : Revisioning employees as active crafters of their work. Academic of Management, 26, 179-201.

Wrzesniewski, A., Dutton, J. E., \& Debebe, G. (2003). Interpersonal sensemaking and the meaning of work. Research in Organizational Behavior, 25(03), 93-135.

Wrzesniewski, A., Mccauley, C., Rozin, P., \& Schwartz, B. (1997). Jobs, careers, and callings: People's relations to their work. Journal of Research in Personality, 31, 21-33.

Zillinger, M., Jonasson, M., \& Adolfsson, P. (2012). Guided tours and tourism. Scandinavian Journal of Hospitality and Tourism, 12(1), 1-7.

\section{Copyright Disclaimer}

Copyright for this article is retained by the author(s), with first publication rights granted to the journal.

This is an open-access article distributed under the terms and conditions of the Creative Commons Attribution license (http://creativecommons.org/licenses/by/4.0/). 